\title{
Relações entre gênero e mercado de trabalho de turismólogos em Minas Gerais
}

Gender and labour market relations for tourism graduates in Minas Gerais, Brazil

Relaciones entre género y el mercado laboral de graduados en turismo en Minas Gerais, Brasil

http://dx.doi.org/10.18472/cvt.16n1.2016.1044

Carlos Eduardo Silveira 〈caesilveira@gmail.com >

Professor do Departamento de Turismo da Universidade Federal do Paraná (UFPR), Curitiba, PR, Brasil.

Juliana Medaglia 〈julianamedaglia@hotmail.com >

Professora do Curso de Turismo da Universidade Federal dos Vales do Jequitinhonha e Mucuri (UFVJM), Diamantina, MG, Brasil.

CRONOLOGIA DO PROCESSO EDITORIAL

Recebimento do artigo: 24-abr-2015

Aceite: 09-abr-2016

FORMATO PARA CITAÇÃO DESTE ARTIGO

SILVEIRA, C. E.; MEDAGLIA, J. Relações entre gênero e mercado de trabalho de turismólogos em Minas Gerais. Caderno Virtual de Turismo. Rio de Janeiro, v. 16 n. 1, p. 109-125, abr. 2016.

$$
\text { REALIZAÇÃO }
$$

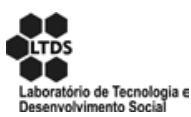

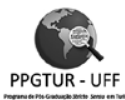

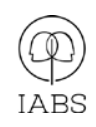

APOIO INSTITUCIONAL

COPPE
EDIÇÃO

PATROCÍNIO

IR⿴囗十⺝RS

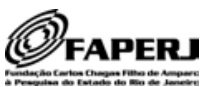




\section{RESUMO}

O turismo é uma atividade humana com implicações marcantes na economia, entre as quais o uso intensivo de mão de obra dos mais diversos níveis. Tomando como ponto de partida o mercado de trabalho de graduados em turismo, com base nas informações dos egressos da formação superior em Turismo realizada no Estado de Minas Gerais, Brasil, o estudo buscou identificar as implicações das questões relacionadas a gênero no âmbito laboral do turismo, a fim de conhecer se há semelhança com outros setores econômicos. Para tanto, utilizou-se de dados levantados por uma pesquisa mais ampla acerca do mercado de trabalho para turismólogos no Brasil, estratificando os dados relativos aos graduados em turismo do Estado, separando as informações entre homens e mulheres, sempre que necessário ou possível. A amostra foi composta de 290 respondentes, sendo 188 mulheres e 102 homens. Os resultados apontam para o fato do mercado de trabalho em turismo, apesar de predominantemente feminino, repetir tendências de outros setores com melhores salários e posições mais elevadas ocupadas por homens. Esses resultados foram inicialmente apresentados no XIII Encontro Nacional de Turismo de Base Local, em 2014, onde foram discutidos e ampliados com as contribuições dos membros do Grupo de Trabalho de Gênero e Sexualidades no Mercado Turístico.

Palavras-chave: Mercado de trabalho. Turismólogos. Gênero. Minas Gerais.

\section{ABSTRACT}

Tourism is a human activity with marked implications in economics, being especially labour intensive in a variety of levels. Taking tourism graduate labour market as starting point, the study aimed at identifying the implications of gender issues in tourism labour market, based on information about higher degree graduated in the State of Minas Gerais, in order to compare whether tourism industry behaves the same way as other economic sectors. In order to do so, data collected in a broader research, which focused on Brazilian tourism labour market as a whole, have been selected extracting information about the state of Minas Gerais separating data using gender as criteria every time it was either needed or possible. The sample counted 290 respondents, being 188 women and 102 men. Even though employment in tourism is largely leaded by women, the results point out that following other sectors pattern, tourism industry tends to pay better wages and have higher positions for men, as compared to women. The results have originally been presentend at the XIII Encontro Nacional de Turismo de Base Local, that took place in Brazil in 2014, being discussed and improved afterwards.

Keywords: Labour market. Tourism Graduates. Gender. Minas Gerais.

\section{RESUMEN}

El turismo es una actividad humana com marcadas implicaciones en la economía, entre ellas el uso intenso de mano de obra de varios nieveles. Partiendo del mercado laboral de profesionales graduados en turismo, o turismólogos, tras la información de los egresados de las licenciaturas en el Estado de Minas Gerais en Brasil, el estudio ha buscado identificar las implicaciones de las cuestiones de género en el ámbito laboral del turismo, con fines de conocer si hay similitud con otros sectores. Para tanto, se ha utilizado datos levantados por una amplia investigación a cerca del mercado laboral trabalho para turismólogos en Brasil, estratificando los datos relativos a los graduados en turismo de ese estado, separando las informaciones entre hombres y mujeres, siempre que necesário o posible. La muestra ha sido compuesta de 290 respondientes, 188 mujeres y 102 homens. Los resultados apuntan para el hecho que que el mercado de trabajo en turismo, a pesar de predominantemente femenino, repite tendéncias de otros sectores con mejores sueldos y posiciones más elevadas ocupadas por hombres. Eses resultados inicialmente han sido presentados en le XIII Encontro Nacional de Turismo de Base Local, en 2014, donde han sido discutidos y ampliados con las contribuiciones de los miembros del Grupo de Trabalho de Gênero e Sexualidades no Mercdo Turístico.

Palabras claves: Mercado laboral. Licenciados en turismo. Género. Minas Gerais. 


\section{Introdução}

O turismo como atividade humana que é, convive, reproduz e intensifica a realidade que o cerca, tanto nas relações pessoais quanto nas profissionais. O vínculo da atividade com o meio permite um elevado número de discussões acerca do grau em que a atividade turística influencia e em que é influenciada pelo contexto no qual se desenvolve ou que se faz presente. Independentemente de ser causa ou consequência, o que se pode assegurar é que o turismo não está alheio à realidade social, mesmo que não seja protagonista na criação de políticas setoriais.

As questões relativas a gênero na sociedade contemporânea são, da mesma forma, influenciadas pela atividade turística, ao mesmo tempo em que a influenciam. Richter (1998) comenta que há uma relação entre turismo e gênero no sentido de serem até pouco tempo temas negligenciados por estudos das ciências políticas, mencionando que o reconhecimento das variações no comportamento político entre homens e mulheres tornou-se objeto de pesquisa somente após a Segunda Guerra, e que o turismo, ainda que venha atraindo mais atenção dos cientistas sociais, continua defasado no que diz respeito aos estudos políticos.

As convergências entre os estudos de ambas as áreas dependem sempre do foco que se dê, a cada uma, e à relação proposta. No turismo, por exemplo, a realidade que cerca os turistas e suas necessidades traria possibilidades de pesquisas possivelmente relacionadas a produtos para públicos específicos, entre as diferentes faixas etárias e preferências, sendo as publicações mais frequentes as que dizem respeito a características de destinos turísticos e produtos voltados ao público LGBT ${ }^{1}$. Por parte da comunidade receptora, a aderência às questões de gênero normalmente está relacionada aos impactos do turismo sexual e sobre a exploração em destinos em cuja prática seja frequente ou conhecida.

Há, entretanto, um enfoque que possui igualmente importância, ainda que seja pouco explorado, que trata das relações profissionais em áreas vinculadas ao turismo e à vulnerabilidade destas às tradições sexistas.

Este último enfoque é o que será exposto neste estudo, como fruto da interpretação de uma pesquisa sobre o mercado profissional de turismólogos. A pesquisa original foi realizada em âmbito nacional, voltada aos graduados em turismo, com um total de 1.360 questionários válidos, respondidos por meio do preenchimento on-line para o qual se utilizou a ferramenta Forms do Google ${ }^{\oplus}$ Drive. O levantamento não possuía foco específico na questão do gênero sendo o artigo que segue, portanto, resultado do recorte desses dados a respeito de Minas Gerais (MG), local de formação de 290 respondentes, 188 mulheres e 102 homens. Esse recorte enfoca a visão mais tradicional de gênero, fruto da evolução do papel da mulher no mercado de trabalho, especialmente após a Revolução Industrial e, mais intensamente, após a Segunda Guerra Mundial (SILVA, 2000). Como os dados nacionais da pesquisa sobre o mercado para egressos em turismo ainda não foram publicados, optou-se por iniciar os desdobramentos da pesquisa original no Estado onde atuam os autores, ainda mais considerando o fato deste ter representado o maior contingente de respondentes da pesquisa geral.

A princípio, tomou-se como base para o recorte a informação referente à Instituição de Ensino Superior - IES, em que o respondente afirmou ter se formado, utilizando-se como critério considerar os que

\footnotetext{
1 A sigla LGBT é habitualmente descrita como sendo “Lésbicas, Gays, Bissexuais e Transexuais". Lanzarini e Rail (2010) utilizam a forma ampliada da sigla, LGBTTT - lésbicas, gays, bissexuais e transexuais/travestis/transgêneros, que é mais abrangente e atual. Contudo, por não ser esse o foco do presente artigo, optou-se pelo uso da sigla mais comumente veiculada.
} 
tenham se graduado em IESs sediadas no Estado de Minas Gerais. A amostra foi obtida por exaustão, uma vez que a pesquisa foi mantida no ar entre os dias 26 de março e 30 de abril de 2012, sendo divulgada pelos mailings de entidades ligadas à profissão de turismólogos, como a Associação Brasileira de Bacharéis em Turismo - ABBTUR, o Instituto Brasileiro de Turismólogos - IBT e a Associação Nacional de Pesquisa e Pós-graduação em Turismo - Anptur. Além disso, houve divulgação por meio de redes sociais e e-mails pessoais entre grupos de turismólogos. A amostra não segue, portanto, critérios estatísticos rígidos e não há pretensão de que seja representativa. Contudo, considerando que não existe um dado oficial acerca do número de turismólogos formados em Minas Gerais (tampouco no Brasil), mas que por aproximação esse número não extrapola 100.000 egressos, considerou-se tratar de uma população pequena, seguindo os padrões propostos por Rea e Parker (2002), o que, em um nível de confiança de 99\% teria um intervalo de confiança menor do que $10 \%$ para mais ou para menos. A partir da ferramenta proposta por Santos ${ }^{2}$ chegou-se a um erro amostral de 5,76\%, dentro de um nível de confiança de 95\%, para uma população desconhecida.

Como a questão acerca do próprio mercado de trabalho para turismólogos é pouco explorada, o trabalho que segue inicia tratando de temas mais amplos que abordam algumas características dos profissionais da área, para, na sequência, traçar comparações entre homens e mulheres graduados em turismo em Minas Gerais, a fim de discutir a relação existente entre gênero e turismo nesse âmbito no Estado.

\section{Breve panorama sobre o mercado profissional em turismo}

O turismo visto como fenômeno social e econômico de deslocamento de pessoas por vontade própria a lugares distintos dos seus de residência por um tempo determinado, é um fato para boa parte da população que sequer questiona seus conceitos ou nuances. Sob o ponto de vista acadêmico o tema é bastante explorado tendo gerado um sem-número de debates e teorias.

Em termos de atuação profissional, entretanto, há uma lacuna de estudos sobre o mercado de profissionais da área de turismo de qualquer nível de formação. A falta de informação acerca do mercado de trabalho talvez tenha origem na própria característica dualizada da formação superior em turismo, caracterizada no Brasil pelos cursos seguidores da tradição pesquisadora e o de tradição mercadológica. Segundo Matias (2002), o primeiro curso superior de turismo no Brasil foi o da Universidade Anhembi (na época Faculdade do Morumbi), sucedido por outras instituições privadas que zelavam pela qualificação do profissional da área. Quando a Universidade de São Paulo criou seu curso, pouco tempo depois, direcionou este para as questões mais acadêmicas da área, e estabeleceu-se o divisor de águas entre os cursos voltados à pesquisa e os voltados ao mercado, nos dois extremos, acompanhados posteriormente por um elevado número de cursos que poderiam ser chamados de mesocêntricos (para prestar homenagem ao teórico Plog) por se estabelecerem em algum lugar entre o academicismo "uspiano" e o foco mercadológico da Anhembi. É interessante que a inserção profissional não tenha sido tema frequente de investigações pela falta de interesse em pesquisa, de um lado, e de mercado, do outro.

O fato é que a área profissional de turismo possui uma infinidade de funções e cargos, que não são, em sua maioria, funções notoriamente ligadas à formação superior em Turismo, como mencionam Barretto

2 Disponível em: 〈http://www.calculoamostral.vai.la〉. Acesso em: 05 mai. 2014 
et al. ao dizerem que "o turismo gera empregos, porém, devemos reconhecer que é quase impossível que todas essas funções sejam exercidas por pessoas com uma mesma formação" (BARRETTO et al., 2004, p. 36), comparando o turismo com áreas como a de habitação, por exemplo.

Há, não obstante, uma gama de funções tradicionalmente vinculadas aos bacharéis em turismo e aos turismólogos. Este último termo é decorrente de campanhas de profissionalização da formação levadas adiante por associações com funções de entidades de classe em momentos alternados dos últimos 40 anos da história da profissão no Brasil, culminando, recentemente, com a inclusão do termo turismólogo à Classificação Brasileira de Ocupações - CBO do Ministério do Trabalho e Emprego - MTE, tendo como sinônimos Analista de Turismo, Consultor em Turismo, Gestor em Turismo, Planejador de Turismo, todos sob o código 1225-20 da CBO.

Ainda que muitas atividades relacionadas ao turismo tenham origem em formação técnica ou até mesmo em treinamentos e cursos de capacitação, o foco deste artigo diz respeito aos ofícios decorrentes da formação superior em turismo, hoje assistida por três modalidades - o tradicional bacharelado, o tecnólogo (que vem se popularizando em virtude de ser mais breve) e a licenciatura. No caso desta última, atualmente a oferta se dá somente em uma instituição - na verdade um consórcio, de IESs, o Cederj no Estado do Rio de Janeiro, não tendo feito parte, portanto, da pesquisa aqui apresentada, por estar fora do âmbito geográfico proposto.

Em todos os casos estudados e de acordo com Matias (2002; 2005), há um consenso acerca da superioridade da proporção de mulheres que cursam turismo, o que é perceptível no contexto dos cursos e comprovável por meio das pesquisas realizadas. Há indícios, inclusive, de maior participação das mulheres no mercado turístico. Richter (1998) coloca que no mercado norte-americano a participação laboral feminina na indústria do turismo perfaz 52\% do total, o que é bastante representativo quando comparado aos $44 \%$ dos empregos formais como um todo. Mesmo assim a quantidade de empregos não assegura o controle do mercado demonstrando a mesma tendência de desequilíbrio de gênero percebida em outros setores.

\section{Questões de gênero e turismo}

Para fins de definição deste trabalho adota-se o conceito de Bandeira, para quem "entende-se por gênero o conjunto de normas, valores, costumes e práticas através das quais a diferença biológica entre homens e mulheres é culturalmente significada" (BANDEIRA, 2005, p. 7). Outra autora acrescenta que, para além das questões culturais, enquanto prática social "ao se afirmar a construção social dos gêneros, coloca-se que as identidades e papéis masculino e feminino não são um fato biológico, vindo da natureza, mas algo construído historicamente e que, portanto, pode ser modificado" (MORAES, 2005, p. 19). A ideia da construção histórica, é corroborada por Lunardi et al. (2015, p. 336), que afirmam que as questões de gênero são representadas "pelo patriarcado, pois ele é a base do sistema de gênero, na medida em que neste as relações são hierarquizadas entre seres socialmente desiguais”, mas que, assim como esse processo social foi construído, pode ser modificado. As questões históricas sempre imputaram às mulheres, na maioria das sociedades, a responsabilidade pelo que seja relacionado ao lar e aos cuidados familiares.

Até o século XVIII, segundo Foucault (apud SILVA, 2000), não havia parâmetros para tratar a questão da sexualidade, sendo esta, portanto, um tema presente a partir da modernidade e da pós-modernidade. 
Ainda assim, os primeiros estudos baseavam-se nos conceitos compartivos, na estrutura de monismo sexual, em que as mulheres eram adaptações do modelo masculino, tido então como sendo o padrão ideal. Segundo Vaquinhas (2015), os estudos das mulheres e de gênero tiveram um impulso a partir dos anos 1970 decorrentes dos movimentos feministas, enfocando o estudo de um passado coletivo de ostracismo.

Em termos laborais, na história mais recente, com a industrialização e a urbanização, segundo Melo (2005), a mulher e sua família são alijadas da esfera produtiva, criando-se a figura moderna da dona de casa, retirando-a de funções economicamente exercidas pelas famílias, até então. Simbolicamente, o trabalho doméstico passa a ser acessório, e o "paradigma, da naturalidade da divisão sexual do trabalho, impõe às mulheres a responsabilidade pelo espaço doméstico, com um ônus alto pelo conjunto das funções reprodutivas" (MELO, op. cit., p. 4). A autora ainda complementa que o próprio aumento da participação feminina no mercado não aliviou esse ônus doméstico e muito menos colocou em cheque a estrutura familiar patriarcal. A construção social dos gêneros, segundo Moraes (2005), tem uma base material (e não apenas ideológica) que se expressa na divisão sexual do trabalho. A mulher segue ausente das esferas de representação política onde e, por conseguinte, das (tomadas de) decisões com impactos sobre a coletividade (MELO, 2005). Moraes (op. cit., p. 13) acrescenta que "a valorização diferenciada do trabalho realizado por homens em detrimento do realizado por mulheres é explicada por um conjunto de autoras, pela existência da hierarquização entre os gêneros". Essa hierarquia tem efeito explícito no mundo do trabalho. Segundo as estatísticas da Organização das Nações Unidas (ONU), as mulheres realizam dois terços do trabalho no mundo, recebem um décimo da receita e possuem um centésimo das propriedades (RICHTER, 1998). Ainda segundo a autora não existem estatísticas relacionadas à indústria do turismo, mas a desigualdade parece ser a norma na maioria dos setores.

O que se tem de informação geral é que, no Brasil, as mulheres recebem em média metade do salário dos homens (as mulheres negras metade do salário do que ganham as brancas). A Organização Internacional do Trabalho (OIT) considera que "a situação das mulheres está melhorando e, se o ritmo se mantiver, em 475 anos conseguiremos a igualdade salarial entre homens e mulheres" (LOURO, 1997 apud MORAES 2005, p. 14). A falta de dados é corroborada pela pesquisadora brasileira da Universidade de Brasília - UnB, Helena Costa, que colabora com o grupo de pesquisa português Gestour. Segundo ela,

\footnotetext{
As desigualdades salariais entre homens e mulheres aumentam proporcionalmente ao tempo de escolaridade, o que indica que o retorno dos investimentos educacionais é diferenciado entre os sexos. Segundo dados do IBGE, as mulheres com grau de escolarização igual ou inferior a 3 anos de estudo ganham menos que os homens com o mesmo grau de escolaridade - 61,5\% - enquanto as mulheres com maior grau de escolarização (11 ou mais anos de estudo) ganham 57,1\% do salário dos homens" (BANDEIRA, 2005, p. 18).
}

No que diz respeito ao tema, não há resultados publicados acerca da relação entre formação e mercado de trabalho em Turismo no Brasil, mas a experiência portuguesa mostra que:

\begin{abstract}
No que concerne à situação profissional dos diplomados em Turismo em Portugal verificou-se que são as mulheres que revelam maiores dificuldades de inserção no mercado laboral. [...] Em relação ao salário mensal líquido, verificou-se que, em média, as mulheres ganham menos 16,8\% do que os homens e que, independentemente do ramo de atividade onde estejam empregadas ou independentemente da região de naturalidade, de estudo ou de residência, auferem salários mensais médios mais baixos do que os seus pares (Disponível em: <http://www.genderintourism. com/global.html>. Acesso em: 06 mai. 2014).
\end{abstract}

O setor de turismo, em todo o mundo, é fortemente baseado em pequena escala, o que, segundo comenta Richter (1998) até certo ponto, joga a favor das mulheres na área. Segundo a autora, nos Estados Unidos as mulheres dominam a propriedade de agências de viagem, mas, por outro lado, os homens controlam os principais setores da economia no turismo. Segundo Panosso Netto et al., 
“é fato que o conhecimento em turismo está governado e liderado pelos homens, mas não porque as mulheres se excluíram da área, mas, sim, porque por muito tempo foram excluídas. No desenvolvimento prático do próprio turismo também há preponderância dos homens, o que traz um grande viés" (2012, s.p.).

Ante a inexistência de dados secundários que descrevam a realidade brasileira e, mais especificamente, mineira, faz-se uso do extrato dos graduados em turismo em instituições mineiras, dos dados da pesquisa realizada com os turismólogos graduados no Brasil, separando, sempre que necessário ou viável, os dados por sexo do respondente.

\section{0 mercado de trabalho do turismólogo formado em minas gerais e as questões relacionadas a gênero}

Os dados levantados por meio de respostas on-line aproximam a realidade mineira do que se tem de informação acerca da proporção de homens e mulheres que cursam Turismo. Como é possível perceber no gráfico a seguir, a proporção de respondentes do sexo feminino é muito superior.

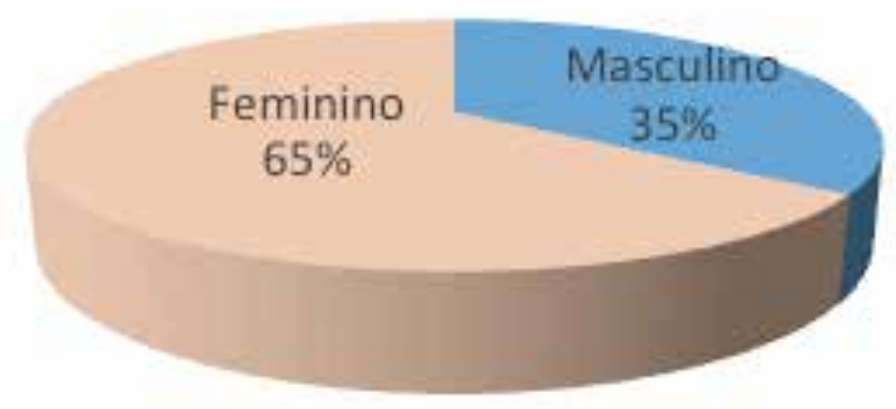

Gráfico 1 - Proporção de homens e mulheres entre os respondentes Fonte: Elaboração própria

A proporção de 65\% de mulheres para 35\% de homens aproxima-se bastante dos dados expostos por Matias em dois momentos distintos (MATIAS, 2002; 2005), e vão ao encontro do senso comum, de que o turismo é uma área de formação predominantemente feminina.

No que se refere à faixa etária da amostra, percebe-se abaixo a predominância da faixa etária dos 22 a 33 anos. 


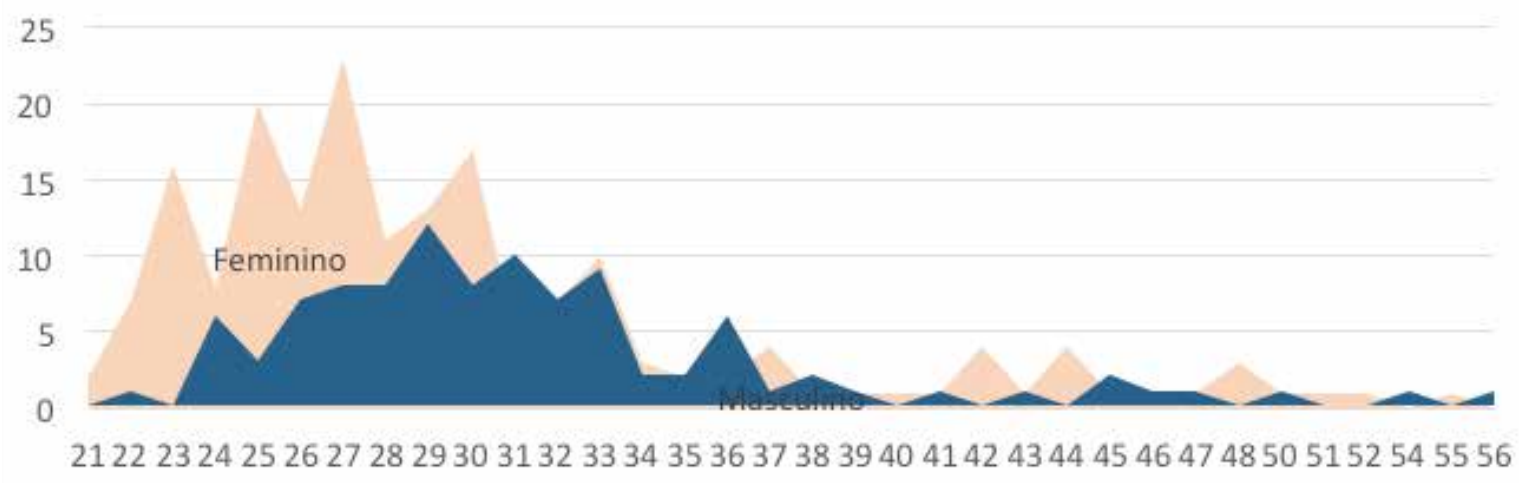

\section{Gráfico 2 - Sexo e Idade}

Fonte: Elaboração própria

A predominância da faixa etária de adultos jovens na amostra obtida tem mais de um viés. Em primeiro lugar pode-se inferir que tenha havido nos últimos anos um elevado número de egressos de cursos superiores de turismo, o que condiz com a realidade. Entretanto, há que se considerar que essa faixa de respondentes tem maior intimidade com a tecnologia da informação e são mais ligados à tecnologia, o que favoreceu a habilidade em responder a pesquisa na forma como ela foi apresentada.

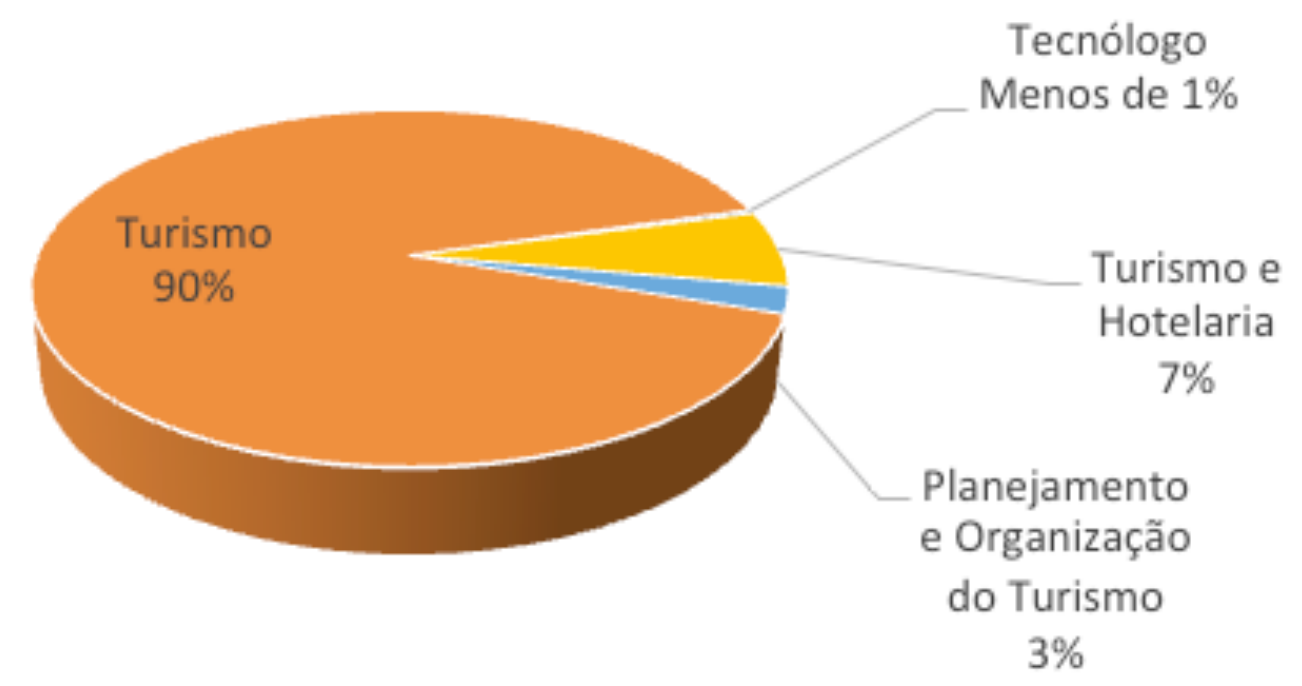

\section{Gráfico 3 - Títulos dos cursos realizados Fonte: Elaboração própria}

Há na atualidade uma variedade significativa de opções de cursos superiores, inclusive na área do turismo. Contudo, percebe-se que em termos de formação no ensino superior, o bacharelado está ainda muito à frente do tecnólogo em número de egressos (somente um dos respondentes entre os 290 cursou 
um tecnólogo). Além disso, pode-se notar que o título mais comum de bacharelado é simplesmente em "Turismo", com 90\% de participação na amostra. É interessante ressaltar também que no Estado de Minas Gerais todos os respondentes graduaram-se em regime presencial, demonstrando que há ainda baixa inserção do ensino a distância na área.

Minas possui (ou já possuiu) alguns dos mais antigos bacharelados em Turismo do Brasil. O Gráfico 4 abaixo mostra, especialmente, a concentração da amostra oriunda de cursos sediados em Belo Horizonte.

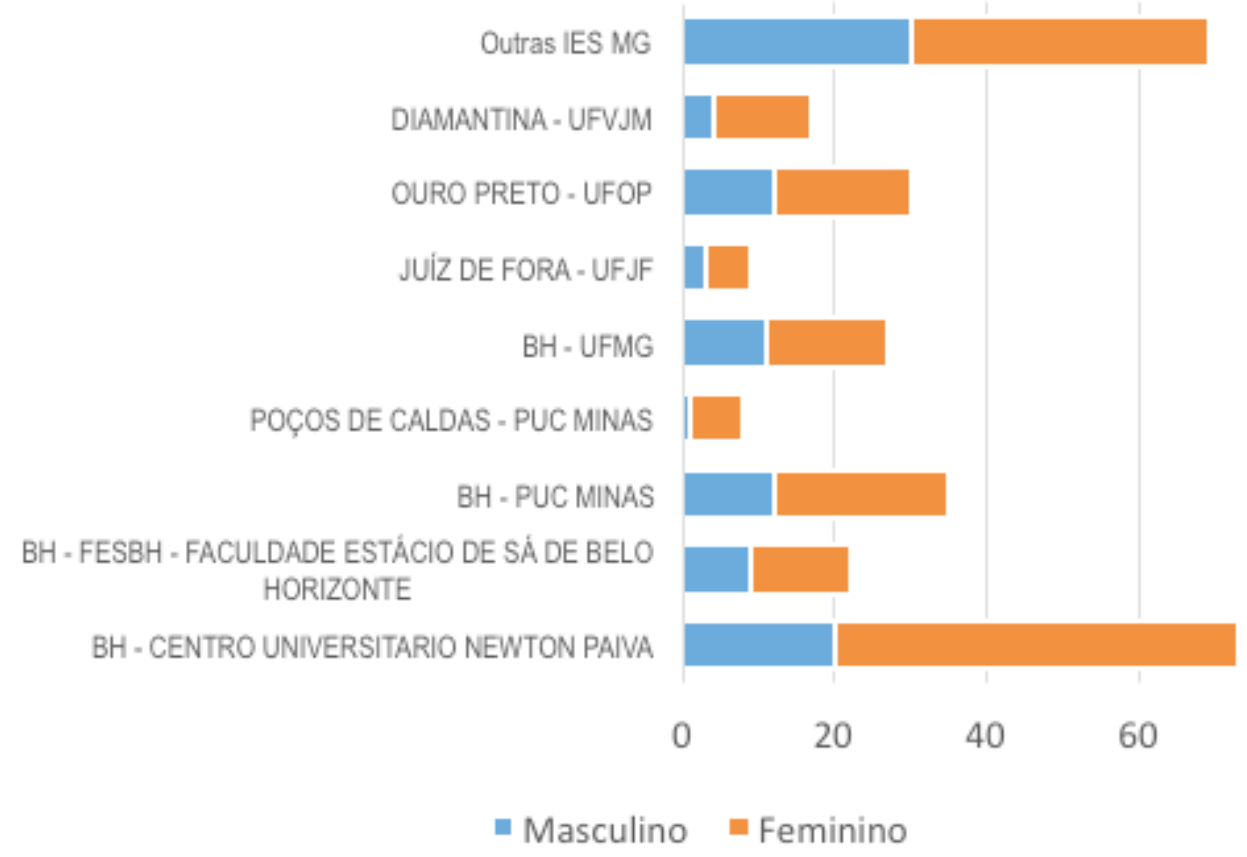

\section{Gráfico 4 - IES em que estudou (homens e mulheres) \\ Fonte: Elaboração própria}

Percebe-se que em todas as IES mencionadas há número maior de respondentes do sexo feminino. Entretanto, mais do que demonstrar a distribuição por gênero entre as IES mais citadas pelos respondentes, o Gráfico 4 aponta para a concentração destes na capital do Estado e, em especial, no Centro Universitário Newton Paiva. Esse Centro Universitário teve o curso mais antigo de Minas Gerais, e deve ter influenciado o pensamento turístico mineiro, a exemplo do que aconteceu com as linhas de pensamento no País, conforme constatado em Curitiba com a Universidade Federal do Paraná - UFPR (MEDAGLIA; SILVEIRA, 2010).

O gráfico seguinte não tenciona comparar os salários masculinos e femininos da área do turismo, já que a amostra de mulheres supera em muito a de homens e os dados não são apresentados em percentuais. O que se busca é relacionar a faixa de renda por tempo de formado, separando-a por sexo do respondente a fim de possibilitar inferências mais claras. 


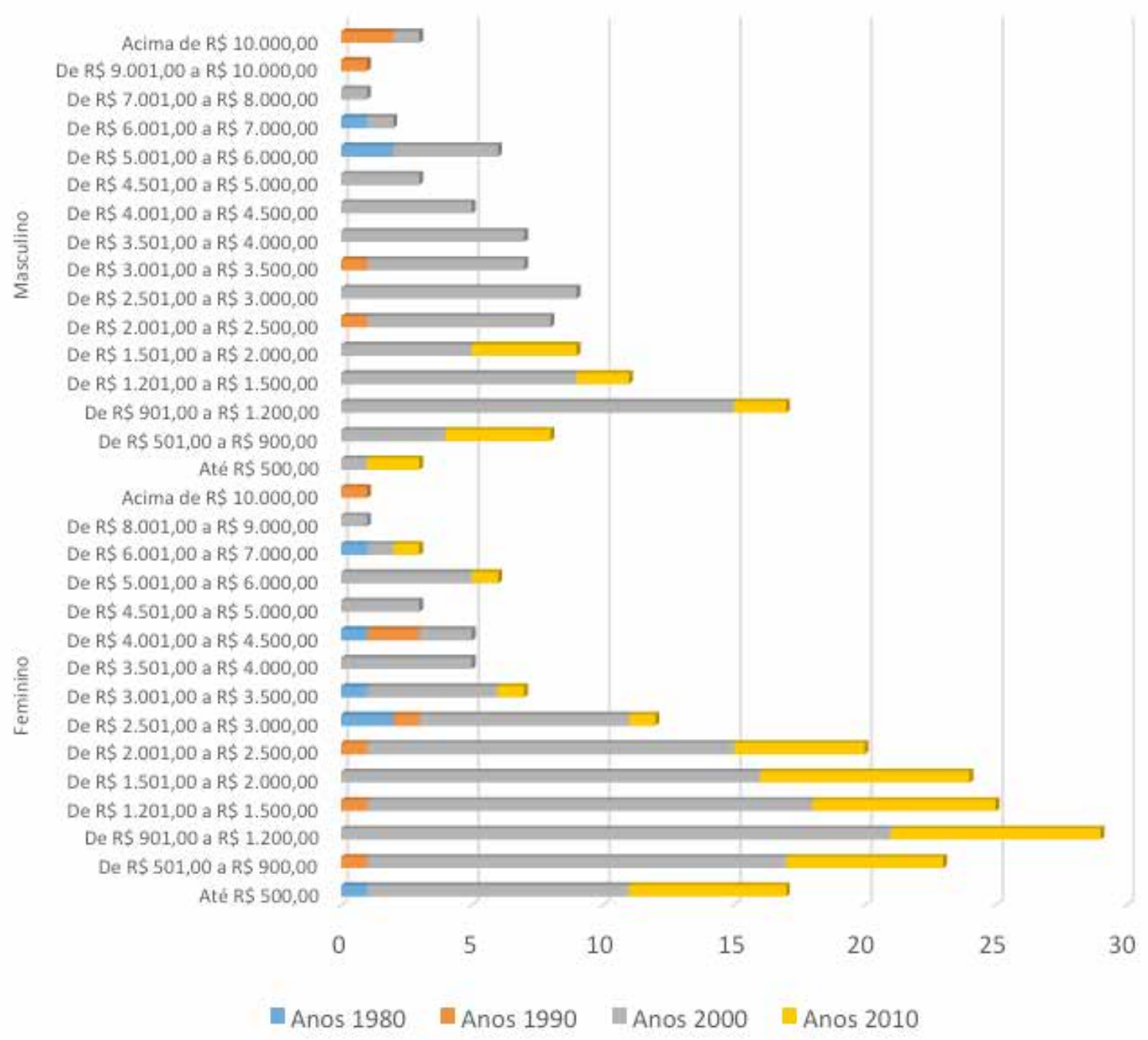

\section{Gráfico 5 - Faixa de renda por tempo de formado} Fonte: Elaboração própria

Há algumas observações acerca do Gráfico 5 que saltam aos olhos, como o fato de apenas mulheres formadas nos anos 1980 terem, no período da pesquisa, renda até $\mathrm{R} \$ 500,00$, além de participarem de outras faixas inferiores aos homens, formados na mesma época. Em contrapartida, há também exemplos de mulheres formadas a menos tempo que se inserem em faixas de renda mais altas, o que não acontece com os homens da amostra. De qualquer modo, o mais perceptível é que o tempo de formado, nos dois casos, tende a ser um fator que incide positivamente no aumento da renda, em ambos os sexos.

Outro fator que gera impacto positivo na renda é o nível de formação e de cursos realizados após formado. O gráfico abaixo apresenta os dados gerais (independente do sexo dos respondentes) acerca da amostra. 


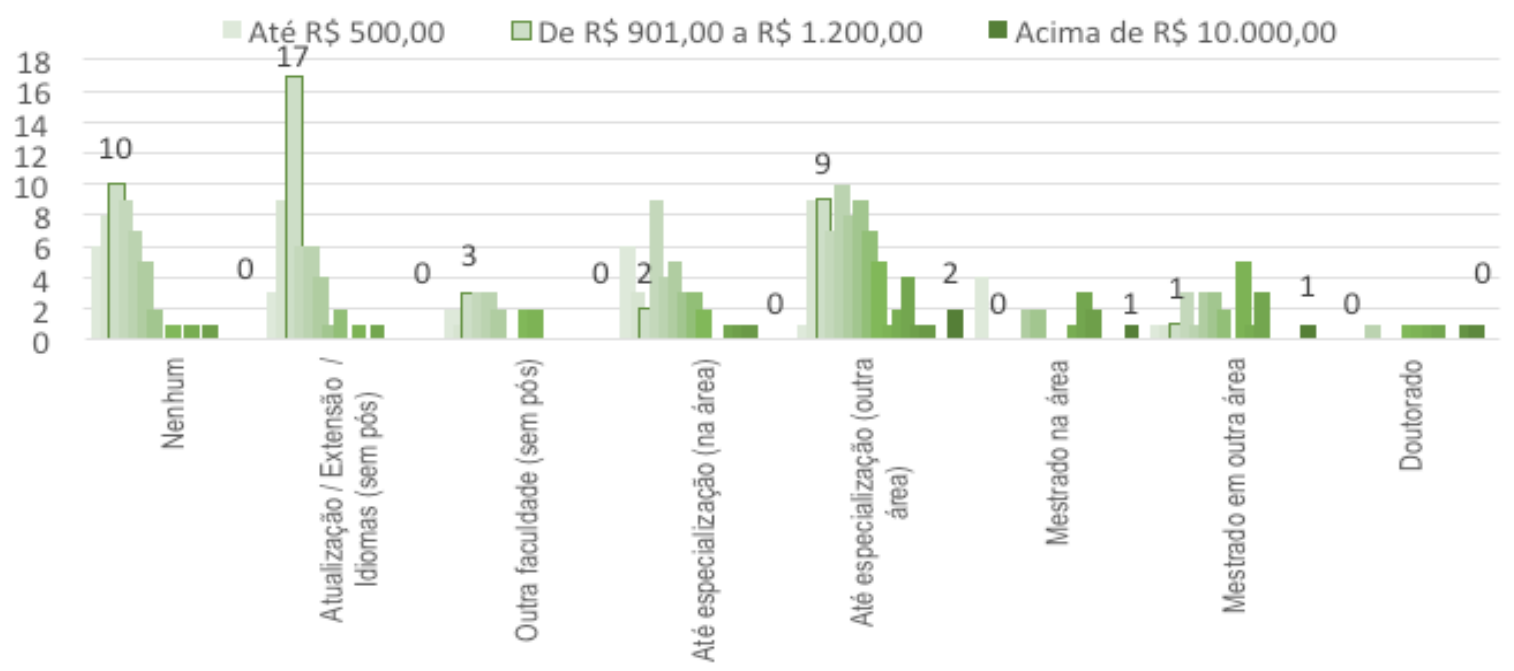

\section{Gráfico 6 - Faixas de renda por tipo de curso após formado Fonte: Elaboração própria}

Mais do que um detalhamento, a proposta deste gráfico é o de informar visualmente a faixa de renda de acordo com cada nível de formação. Nesse sentido, as tonalidades das colunas vão escurecendo à medida que os salários vão aumentando. Destacam-se no gráfico três faixas principais de renda - a mínima levantada, de R \$500,00; a moda na amostra, que representa dos salários entre $\mathrm{R} \$ 901,00$ e $\mathrm{R} \$ 1.200,00$ (esta contornada no gráfico para que possa ser visualizada) e os salários mais altos, representados pelas colunas mais escuras.

O que se percebe é uma diminuição quantitativa no sentido das formações mais aprofundadas, mas, em compensação, uma tendência à participação proporcional das faixas de renda mais altas à medida que cresce o nível de formação. Isso vai ao encontro do que havia sido levantado em pesquisa semelhante com os egressos dos cursos superiores em Curitiba (MEDAGLIA; SILVEIRA, 2010) e interessa ao tema abordado neste artigo, uma vez que foi percebido que turismólogos do sexo masculino têm, proporcionalmente, as maiores titulações na amostra utilizada, como pode ser percebido no gráfico a seguir. 


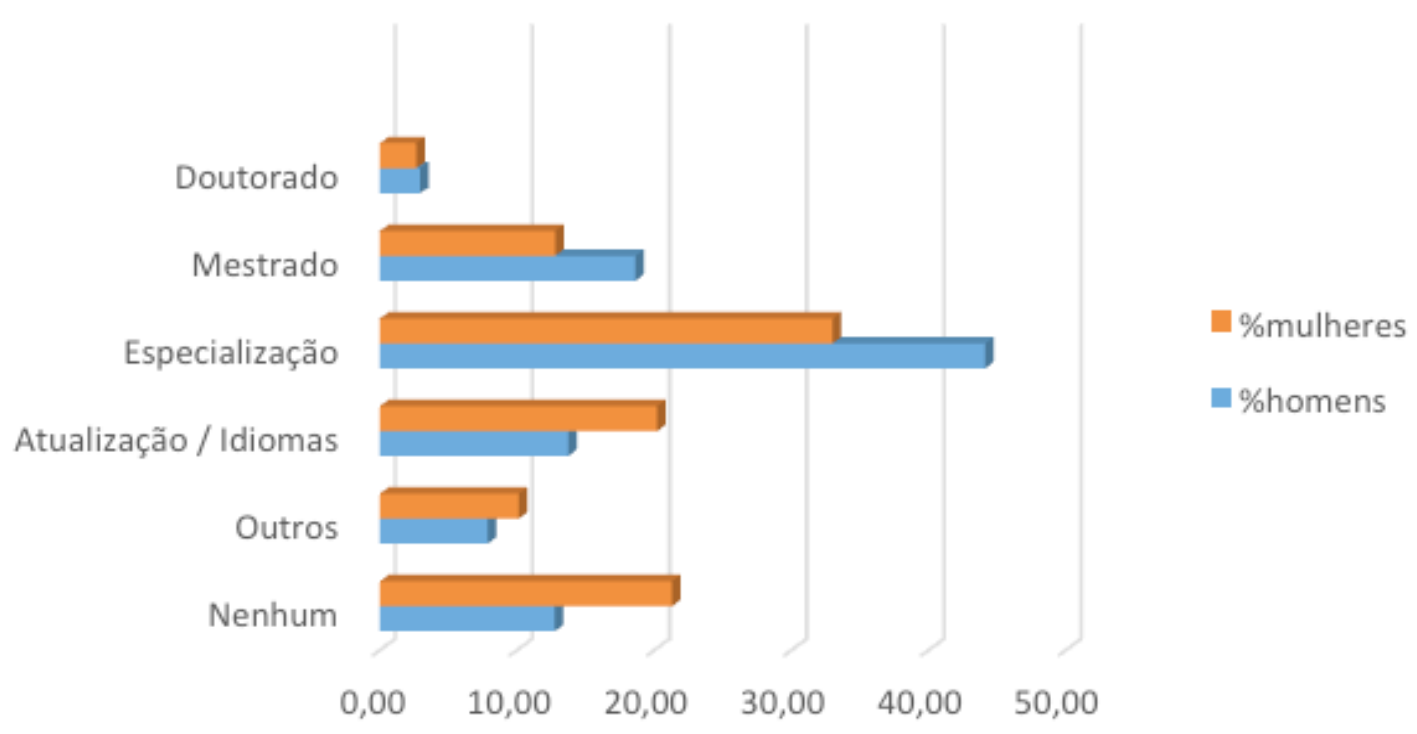

\section{Gráfico 7 - Cursos após formado, por sexo Fonte: Elaboração própria}

Conforme mencionado, o gráfico acima não trata de números absolutos, mas de proporções, e, dentro dessa lógica, a partir da especialização os homens passam a superar proporcionalmente as mulheres. Outros estudos já mencionados apontam para uma redução da distância entre os salários de homens e mulheres de acordo com o tempo de estudo. A amostra desta pesquisa, contudo, não permitiu uma análise nesse sentido devido ao reduzido número de respondentes com pós-graduação stricto sensu não possibilitar generalizações.

Buscou-se também identificar, na pesquisa, qual o setor que mais emprega turismólogos. Não surpreende que a iniciativa privada encabece a lista com 41\%, uma vez que diversos autores (BENI, 2001; LICKORISH; JENKINS, 2000) comentam sobre a capacidade empregadora do turismo na indústria. O setor público representou $31 \%$ dos respondentes, e os que são da iniciativa privada, mas prestam serviço ao setor público somam 7\%. Por fim, os que atuam em setor misto equiparam-se aos do terceiro setor, cada um com $8 \%$.

Separando essa amostra entre homens e mulheres por faixa de renda, considerando cada faixa como $100 \%$ a fim de comparar a participação de cada sexo na renda em questão, tem-se o gráfico que segue. 


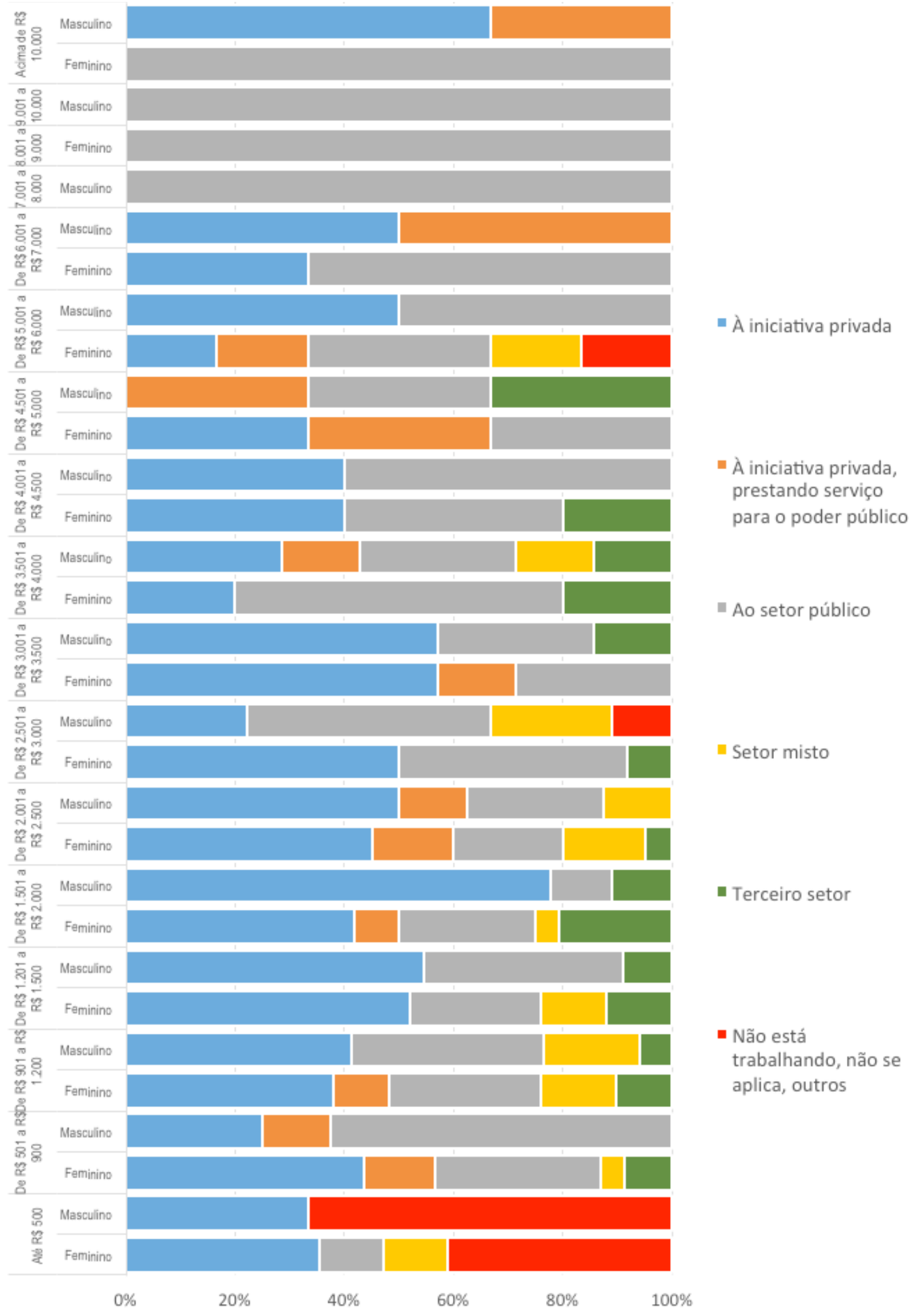

\section{Gráfico 8 - Setor em que atua $x$ renda por sexo} Fonte: Elaboração própria

É interessante notar que o setor público está presente em todas as faixas de renda, sendo o único presente em algumas das mais elevadas. Nessas faixas, percebe-se o senso de equidade do serviço público, 
já que os maiores salários femininos estão justamente em órgãos governamentais. Em termos de salários femininos, o teto no terceiro setor foi a faixa de $\mathrm{R} \$ 4.001,00$ a $\mathrm{R} \$ 4.500,00$ e na iniciativa privada, de $\mathrm{R} \$$ $6.001,00$ a $\mathrm{R} \$ 7.000,00$. Nestes o teto da remuneração dos respondentes do sexo masculino foi um nível acima no terceiro setor, de $\mathrm{R} \$ 4.501,00$ a $\mathrm{R} \$ 5.000,00$, e na iniciativa privada quatro níveis acima, chegando à faixa acima de $\mathrm{R} \$ 10.000,00$, o que extrapola em muito a média de $16,8 \%$ de gap levantado pelo Gentour em Portugal.

O quadro que segue apresenta as divisões por salários e por sexo, de acordo com as atividades profissionais principais mencionadas pelos respondentes.

Quadro 1. Comparação entre salários e áreas de atuação, por sexo

\begin{tabular}{|c|c|c|c|c|c|c|c|c|c|c|c|c|c|c|c|c|c|c|}
\hline Atuação Profissional & 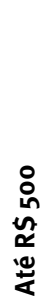 & 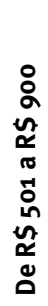 & 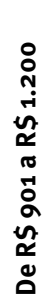 & 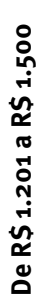 & 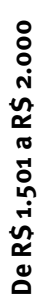 & 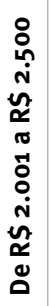 & 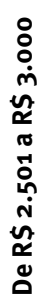 & 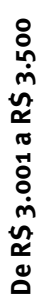 & 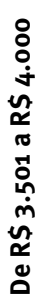 & 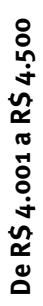 & 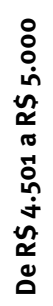 & 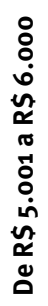 & 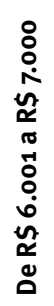 & 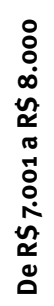 & 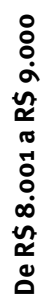 & 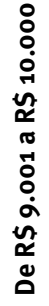 & 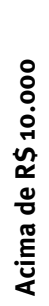 & $\begin{array}{l}\bar{\pi} \\
\frac{\pi}{\pi} \\
\stackrel{\pi}{0}\end{array}$ \\
\hline Agências ou Operadoras & & 1 & 5 & 6 & 9 & 3 & 3 & 1 & 1 & & & & & & & & & 29 \\
\hline Feminino & & 1 & 2 & 4 & 7 & 3 & 2 & & & & & & & & & & & 19 \\
\hline Masculino & & & 3 & 2 & 2 & & 1 & 1 & 1 & & & & & & & & & 10 \\
\hline Alimentos e Bebidas & & & & 1 & 1 & 1 & & & & & & & & & & & & 3 \\
\hline Feminino & & & & 1 & & 1 & & & & & & & & & & & & 2 \\
\hline Masculino & & & & & 1 & & & & & & & & & & & & & 1 \\
\hline Consultoria Empresarial & & & & & & 1 & & 2 & & 1 & 1 & & & & & & 1 & 6 \\
\hline Feminino & & & & & & & & & & 1 & 1 & & & & & & & 2 \\
\hline Masculino & & & & & & 1 & & 2 & & & & & & & & & 1 & 4 \\
\hline Consultoria para Destinos & & 1 & & & & 3 & & 2 & & & & & 1 & & & & & 7 \\
\hline Feminino & & 1 & & & & 2 & & 2 & & & & & & & & & & 5 \\
\hline Masculino & & & & & & 1 & & & & & & & 1 & & & & & 2 \\
\hline Docência & & 1 & 1 & & 2 & 2 & 3 & 2 & 2 & 5 & 1 & 6 & 1 & & 1 & 1 & 1 & 29 \\
\hline Feminino & & & 1 & & 1 & 1 & 2 & 1 & 1 & 2 & & 3 & 1 & & 1 & & & 14 \\
\hline Masculino & & 1 & & & 1 & 1 & 1 & 1 & 1 & 3 & 1 & 3 & & & & 1 & 1 & 15 \\
\hline Eventos & & 2 & 2 & 5 & 1 & 4 & & 1 & 1 & & & 1 & & & & & & 17 \\
\hline Feminino & & 1 & 1 & 4 & 1 & 3 & & & & & & 1 & & & & & & 11 \\
\hline Masculino & & 1 & 1 & 1 & & 1 & & 1 & 1 & & & & & & & & & 6 \\
\hline Hospedagem & 1 & 1 & 9 & 3 & 5 & 2 & 2 & 1 & 1 & & & 2 & & & & & 1 & 28 \\
\hline Feminino & 1 & 1 & 7 & & 2 & 1 & 2 & 1 & 1 & & & 1 & & & & & & 17 \\
\hline Masculino & & & 2 & 3 & 3 & 1 & & & & & & 1 & & & & & 1 & 11 \\
\hline Lazer e Recreação & & 1 & & 1 & & & & & & & & & & & & & & 2 \\
\hline Feminino & & 1 & & 1 & & & & & & & & & & & & & & 2 \\
\hline Não estou trabalhando & 14 & 5 & 1 & 2 & 1 & & & & & & & & & & & & & 23 \\
\hline Feminino & 12 & 4 & 1 & 2 & & & & & & & & & & & & & & 19 \\
\hline Masculino & 2 & 1 & & & 1 & & & & & & & & & & & & & 4 \\
\hline $\begin{array}{l}\text { Órgãos oficiais (públicos) da área com } \\
\text { criação e/ou implementação de políticas }\end{array}$ & & 5 & 4 & 3 & 1 & 3 & 2 & & 1 & & & 1 & & & & & & 20 \\
\hline Feminino & & 2 & 2 & 1 & 1 & 2 & & & 1 & & & & & & & & & 9 \\
\hline Masculino & & 3 & 2 & 2 & & 1 & 2 & & & & & 1 & & & & & & 11 \\
\hline
\end{tabular}




\begin{tabular}{|c|c|c|c|c|c|c|c|c|c|c|c|c|c|c|c|c|c|c|}
\hline Atuação Profissional Faixa Salarial & 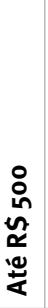 & 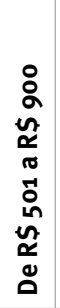 & 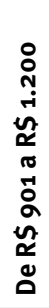 & 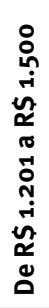 & 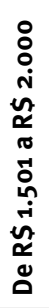 & 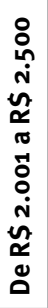 & 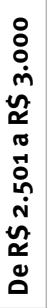 & 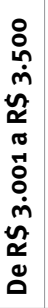 & 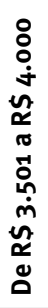 & 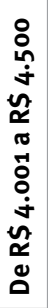 & 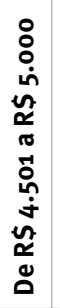 & 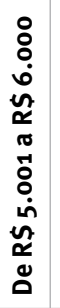 & 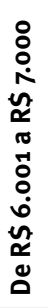 & 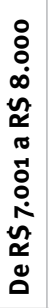 & 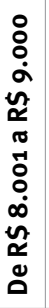 & 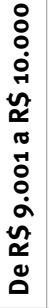 & 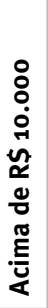 & $\begin{array}{l}\bar{\pi} \\
\frac{\pi}{0} \\
\frac{\pi}{\pi} \\
0\end{array}$ \\
\hline $\begin{array}{l}\text { Órgãos oficiais (públicos) da área em } \\
\text { outros setores }\end{array}$ & & 2 & 1 & 2 & 1 & & 1 & & 1 & & & & & & & & & 8 \\
\hline Feminino & & 1 & 1 & 2 & 1 & & 1 & & & & & & & & & & & 6 \\
\hline Masculino & & 1 & & & & & & & 1 & & & & & & & & & 2 \\
\hline Órgãos oficiais (públicos) de áreas afins & & & 2 & 2 & & 1 & & 2 & & 1 & & & 1 & 1 & & & & 10 \\
\hline Feminino & & & 1 & 2 & & 1 & & 1 & & & & & 1 & & & & & 6 \\
\hline Masculino & & & 1 & & & & & 1 & & 1 & & & & 1 & & & & 4 \\
\hline Outra área ligada a turismo & & 2 & 2 & 3 & 3 & 2 & & & 2 & 1 & 1 & & 1 & & & & & 17 \\
\hline Feminino & & 2 & 2 & 3 & 3 & 2 & & & 1 & 1 & & & 1 & & & & & 15 \\
\hline Masculino & & & & & & & & & 1 & & 1 & & & & & & & 2 \\
\hline
\end{tabular}

Fonte: Elaboração própria

Ainda que a tabela fale muito por si, cabe ressaltar alguns pontos. Em primeiro lugar a predominância das mulheres em praticamente todas as áreas que mais empregam turismólogos. Essa predominância seria esperada em virtude do tamanho da amostra de cada sexo.

Contudo, mesmo em termos de números absolutos pode-se acompanhar a diferença salarial entre os sexos, como no caso das agências de viagens, área com predominância feminina histórica, mas na qual se percebe que as faixas salariais superiores são ocupadas por homens. As exceções são hotelaria e planejamento turístico. Outro dado que chama atenção nessa amostra é a predominância de mulheres na categoria "não estou trabalhando" e o equilíbrio de gênero entre os professores e gestores públicos.

No que diz respeito à hierarquia dentro das organizações e ao empreendedorismo, houve necessidade de reduzir a amostra para os que tenham assinalado somente uma opção, nesse caso, entre 139 mulheres e 78 homens. Os valores foram transformados em percentuais a fim de possibilitarem comparações.

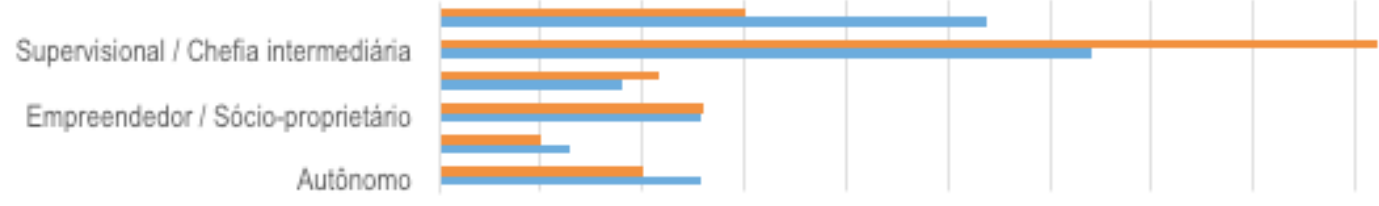

$0,005,0010,0015,0020,0025,0030,0035,0040,0045,0050,00$

\begin{tabular}{|c|c|c|c|c|c|c|}
\hline & Autônomo & Diretoria & $\begin{array}{l}\text { Empreendedor/ } \\
\text { Sócio-proprietário }\end{array}$ & Gerência / chefia & $\begin{array}{l}\text { Supervisional / } \\
\text { Chefia } \\
\text { intermediária }\end{array}$ & $\begin{array}{l}\text { Operacional/ } \\
\text { Linha de frente }\end{array}$ \\
\hline \%mulheres & 10,07 & 5,04 & 12,95 & 10,79 & 46,04 & 15,11 \\
\hline \%homens & 12,82 & 6,41 & 12,82 & 8,97 & 32,05 & 26,92 \\
\hline
\end{tabular}

\section{Gráfico 9 - Postos de trabalho}

Fonte: Elaboração própria

Mesmo que a amostra reduzida não permita conclusões generalizáveis, é interessante a presença massiva masculina em postos operacionais e a superioridade feminina em cargos de chefia até o nível de gerência. 


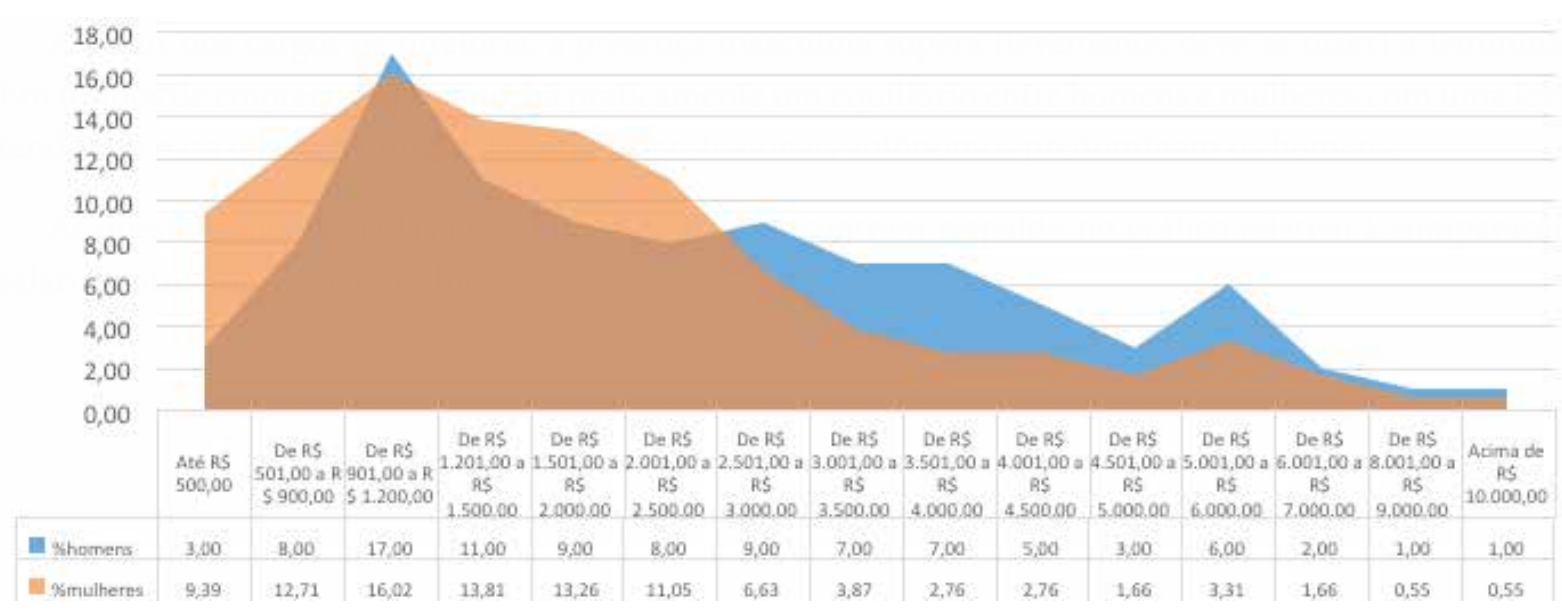

\section{Gráfico 10 - Comparação salarial - homens e mulheres Fonte: Elaboração própria}

Proporcionalmente, apesar da existência de um pico no gráfico masculino nos salários na faixa de $R \$ 901,00$ a $R \$ 1.200,00$, a predominância feminina nos salários até $R \$ 2.500,00$ dá lugar aos homens na liderança dos números relativos aos salários acima de $\mathrm{R} \$ 2.500,00$, com uma vantagem numérica muito pequena nas faixas mais elevadas, mas sempre acima.

É certo que os salários não são garantia de qualidade de vida ou de status social, mas tendem a representar, em termos pecuniários, a tendência de valorização da sociedade em relação aos seus trabalhadores.

\section{CONSIDERAÇÕES FINAIS}

É no mínimo curioso constatar que uma área em que as mulheres dominam numericamente a formação e a participação no mercado de trabalho, tenha características tão parecidas com as outras áreas profissionais, onde predomina o jugo masculino. Considerando que o estudo apresentado baseou-se no extrato do Estado de Minas Gerais de graduados em Turismo para apresentar a questão do gênero no mercado profissional de turismólogos, foi possível perceber muitas semelhanças com as poucas experiências internacionais em turismo que puderam ser levantadas para serem usadas como comparação.

Entre as principais constatações possíveis pela interpretação dos dados apresentados, foi a reprodução do modelo industrial sexista na área do turismo, no qual se percebe o predomínio salarial e de capacitação masculina, em detrimento da superioridade quantitativa feminina. Ressalta-se que o foco do estudo não envolveu questões relacionadas à sexualidade ou ao universo mais amplo LGBT, tendo se restringido ao sexo declarado pelos respondentes por ocasião do levantamento dos dados, ou seja, à sexualidade socialmente externada.

Entende-se que o tema gênero é pouquíssimo explorado em sua zona de aderência com o turismo, e que novos estudos e pesquisas com públicos diversificados poderiam gerar ainda mais dados acerca dessa relação. Contudo, espera-se que esta pesquisa incentive novas iniciativas na área e que o tema possa ser discutido até o ponto de perder o sentido, e que a discrepância entre os gêneros ceda muito antes dos quatro séculos previstos pela Organização Internacional do Trabalho - OIT para sua erradicação no mercado laboral brasileiro. 


\section{Referências}

BANDEIRA, L. Fortalecimento da Secretaria Especial de Políticas para as Mulheres: avançar na transversalidade da perspectiva de gênero nas políticas públicas. Brasília: CEPAL, SPM, 2005.

BARRETTO, M; TAMANINI, E; SILVA, I. P. Discutindo o Ensino Universitário de Turismo no Brasil. Campinas: Papirus, 2004.

BENI, M. Análise Estrutural do Turismo. São Paulo: Senac, 2001.

BRASIL. Ministério do Trabalho e Emprego. Cadastro Brasileiro de Ocupações. Disponível em: 〈http:// www.mtecbo.gov.br/cbosite/pages/pesquisas/BuscaPorTitulo.jsf\#». Acesso em: 06 mai. 2014.

GENTOUR. Gender in Tourism. Projeto Gentour Aproveitamento do quadro de formação das mulheres para o sector do turismo, estudando a mobilidade vertical por razões de natureza ética e económica. Universidade de Aveiro, Portugal. Disponível em: 〈http://www.genderintourism.com/global.html〉. Acesso em: 06 mai. 2014.

LICKORISH, L. J.; JENKINS, C. L. Introdução ao turismo. Rio de Janeiro: Campus, 2000.

LUNARDI, R.; SOUZA, M. de; PERURENA, F. Participação e Decisão no Turismo Rural: uma análise a partir da perspectiva de gênero. Turismo em Análise. USP. v. 26, n. 2, Abril (2015).

MATIAS, M. Turismo: formação e profissionalização - $\mathbf{3 0}$ anos de história. Barueri: Manole, 2002.

. Panorama da Formação Profissional em Turismo e suas Relações com o Mercado de Trabalho no Brasil. In: TRIGO, L. et al. Análises Regionais e Globais do Turismo. São Paulo: Roca, 2005.

MEDAGLIA, J; SILVEIRA, C. E. Reflexões sobre a atuação profissional dos turismólogos e o planejamento do turismo: pesquisa com os egressos dos cursos de turismo de Curitiba, Paraná, Brasil. In: Turismo e Sociedade. UFPR. v. 3, n. 2 (2010).

MELO, H. Relatório Final do Projeto Governabilidad Democratica de Género en America Latina y el Caribe. Brasília: CEPAL, SPM, 2005.

MORAES, E. Construindo a relação gênero e raça na política pública de qualificação social e profissional. Brasília: MTE, SPPE. DEQ, 2005.

PANOSSO NETTO, A; COSTA, H; TRIGO, L. Comunicação sobre Evento: International Conference on Gender issues: implications for leisure and tourism. Turismo: Visão e Ação. v. 14, n. 1 (2012).

REA, L. M.; PARKER, R. A. Metodologia da Pesquisa: do planejamento à execução. São Paulo: Pioneira Thomson Learning, 2002

RICHTER, L. Exploring the political role of gender in tourism research. In: THEOBALD, W. Global Tourism. 2. ed. Oxford: Butterworth - Heinemann, 1998.

SANTOS, G. E. O. Cálculo amostral: calculadora on-line. Disponível em: 〈http://www.calculoamostral. vai.là. Acesso em: 05 mai. 2014

SILVA, S. G. da. Masculinidade na história: a construção cultural da diferença entre os sexos. Psicologia: ciência e profissão. Brasília, v. 20, n. 3, p. 8-15, Set. 2000. Disponível em: 〈http:// www.scielo.br/scielo.php?script=sci_arttext\&pid=S1414-98932000000300003\&lng=en\&nrm=iso>. Acesso em: 23 abr. 2015.

VAQUINHAS, I. M. M. C. M. Museus das mulheres na actualidade: criação, objectivos e o contributo da história. Revista Iberoamericana de Turismo - RITUR, UdG/UFAL. Número Especial, p. 5-26, out. (2015) 